International Journal of Current Microbiology and Applied Sciences ISSN: 2319-7706 Volume 8 Number 05 (2019)

\title{
Role of Hormonal Effects in Men and Women HIV Patients
}

\author{
Vinay Malik*, Tung Vir Singh Arya and Kaushiki Mukhergee \\ LLRM Medical College and Hospital, Meerut, (UP), India \\ Shobhit Deemed University, Meerut, (UP), India \\ *Corresponding author
}

\section{A B S T R A C T}

\section{Keywords \\ Males and Females (pre-menopausal), Age matched controls, Infected HIV patients, HPA \\ Article Info \\ Accepted: \\ 15 April 2019 \\ Available Online: \\ 10 May 2019}

\section{Introduction}

The endogenous glucocorticoids are important in regulating inflammation. Hypothalamic pituitary adrenal axis (HPA) contributes to regulation of $\mathrm{T}$ cell activation in HIV. It is an important pathway through which psychological states and HPA axis influence progression of HIV. HPA regulates secretion of glucocorticoids endogenous hormones with potent anti-inflammatory properties. Chronic stress may lead to decreased glucocorticoid sensitivity and impairment in the ability of HPA axis to regulate the immune system. A potential role of HPA axis in HIV pathogenesis has been reported. Elevated morning cortisol has been associated with rapid disease progression.

An association has been shown between psychological stress, mood and HIV progression, which is probably mediated by molecular messengers of the HPA axis and autonomic nervous system. Besides, HIV progression has been shown to be linked with sympathetic nervous system through various pathways. Lower morning cortisol and flatter diurnal rhythms are associated with greater activation of $\mathrm{CD}^{+}$and $\mathrm{CD} 8^{+} \mathrm{T}$ cells (Deepak Nilsoge Guruswamy et al., 2017). 
The World Health Organization estimates that 14.8 million women are living with human immunodeficiency virus (HIV) type 1 infection and that another 6.2 million women have died of AIDS. Unprotected vaginal intercourse is the most common route through which women are infected with HIV-1. In sexually active women, the levels of estragon and progesterone vary significantly under different natural and therapeutic conditions. During the monthly reproductive cycle, estragon levels steadily rise during the follicular phase and then fall after ovulation during the luteal phase, at which time progesterone levels rise. Women with low circulating levels of estragon secondary to natural menopause or to therapy with depomedroxyprogesterone acetate (DMPA) are more likely to become infected with HIV. It is reported that estragon may reduce transmission of HIV-1 across the vaginal epithelium and/or suppress viral replication after transmission has occurred (Karim $\mathrm{R}$ et al., 2013).

Lack of estragon increases bone resorption, as well as decreasing the deposition of new bone that normally takes place in weight-bearing bones. The amount of estragon needed to suppress this process is lower than that normally needed to stimulate the uterus and breast gland. Estragon down regulates many of the pro-inflammatory cytokines (Tumour necrosis factor alpha, Interleukin-1, Interleukin-6) that increase bone resorption. These pro-inflammatory cytokines have all been found to be elevated in HIV+ individuals and may not be completely suppressed after ART (Nkirukal1 RU et al., 2017). Estragon appears to down-regulate bone-marrow cell expression of receptor activator of nuclear factor kappa-B ligand (RANKL), and upregulate gene expression and protein synthesis of osteoprotegerin (OPG). In pre-menopausal subjects, estragon could attenuate the effects of pro-inflammatory cytokines and RANKL production on osteoclast genesis, thereby mitigating the accelerated bone demineralization associated with HIV infection and treatment. However, the decline in estradiol levels that accompanies menopause would be expected to exacerbate any cytokine-mediated increase in bone (Nkiruka et al., 2017).

\section{Humoral response To HIV}

The humoral immune response occurs later in infection; therefore, the level of antibodies during the acute infection is very low. Nonneutralising antibodies to structural proteins (i.e. P17 and P24) are first to appear and generally do not persist. Later neutralising antibodies specific to proteins, involved in the entry of the virus into the cells, will be generated.

\section{Materials and Methods}

HIV-1 enters the central nervous system (CNS) during the early stages of HIV infection ${ }^{1}$ and has been associated with neurological and neuropsychiatric effects, including major depressive disorder (MDD) and cognitive impairment (CI).

HIV-1 infection targets the central nervous system in subcortical brain areas and leads to high rates of delirium, depression, opportunistic central nervous system infections, and dementia. Long-term HIV replication in the brain occurs in astrocytes and microglia, allowing the virus to hide from antiviral medication and later compromise neuronal function. The associated cognitive disturbance is linked to both viral activity and inflammatory and other mediators from these immune cells that lead to the damage associated with HIV-associated neurocognitive disorders, a general term given for these disturbances. We review the severity and prevalence of the 
neuropsychiatric complications of HIV including delirium, neurobehavioral impairments (depression), minor cognitivemotor dysfunction, and HIV-associated dementia. When examining severity of major depression of HIV/AIDS, most of the studies focus on the association of mood disorders with higher rates of disease transmission, lower rates of compliance, and psychological distress from the disease. Major depression makes individuals more susceptible to contracting HIV and AIDS because of its effect on behaviour. Depression factors into HIV risk since it often impacts insight and judgment in decision-making and may exacerbate substance abuse (Eggers $\mathrm{C}$ et al., 2017).

\section{Results and Discussion}

HIV associated neurocognitive disorder (HAND) was studied by 8 studies either alone or as mixed diagnosis out of which 7 studies reported mild to severe HAND when compared either with healthy control or within HIV positive patients (Kumar et al., 2019; Yusuf et al., 2017; Balaini et al., 2017; Estiasari et al., 2015; Habib et al., 2013; Achappa et al., 2013; Wang et al., 2013). Only a single study conducted by Nyongesa $e t$ al., (2018) reported no significant effect of HIV over neurocognitive skills. Out of 8 studies, 6 studies included patients on HAART for different duration and majorly reported no response. While Balaini et al.,2017 and Nyongesa et al.,2018 found no association between HAND and cART regimen, studies conducted by Yusuf et al.,2017, Achappa et al., (2013), Wang et al., (2013) found mild to severe HAND prevalence irrespective of HAART administration. The positive effect of long term administration of ART over HAND was recorded by Kumar et al., (2019) whereas study performed by Estiasari et al., (2015) reported poor cognitive performance and high
Prevalence rate in absence of HAART treatment. In case of HAND major factors that were found to be associated with poor cognitive performance were long duration of HIV diagnosis, low CD4 count, low educational status, severity of illness, psychiatric diseases and substance use, anemia, low body mass index, increasing age, and female gender.

A total of 6 studies assessed depression and anxiety in PLHIV where 5 studies recorded high prevalence (Adeoti et al., 2018; Ramachandra and Badiger, 2018; Hafeez T, 2018; Betancur et al., 2017; Tesfaw et al., 2016) and one showed no significant occurrence (Gauiran et al., 2018). All these studies included the patients on ART for variable duration, hence higher prevalence of depression and anxiety in these patients indicate no significant effect of treatment. Major correlates demonstrated by these studies include female gender, age, smoking, homosexuality, unprotected sex, unemployment, low CD4 count, nondisclosure of HIV status, perceived HIV stigma, poor social support, HIV stage III, poor medication adherence, divorce, and comorbid TB illness.

Neuropsychological disorders in PLHIV were largely related with stressful life events and diminished social support (Leserman et al., 2002; Ironson et al., 2005). The present review also observed that major correlates for enhanced neuropsychological disorders involve social factors such as being female, HIV stigma, low education and income status, societal isolation, poor family support, smoking and substance use. Larger vulnerability of females towards mental disorders can be attributed to factors such as increased exposure to acute life events, lower social status and network, and financial problem (NACA, 2012). HIV stigma serves as one of the leading factor in increased 
preponderance of depression and anxiety. Stigma results in enhanced fatigue levels, isolation, loneliness and felling of worthlessness (Rodkjaer et al., 2010; Bhate and Munjal, 2014; Berhe and Bayray, 2013). Similarly, social relationship domain not only help in preventing mental disorders but also significantly affect overall QoL in PLHIV as it provides safety, security and financial support. Smoking and substance use bidirectionally indicate status of mental problems as well as disease progression and therefore interventions to stop them are inherent part of HIV management (Chang et al., 2017; Ruggles et al., 2017).

Based upon the present review, the role of HAART in reducing the prevalence of neuropsychological disorders with disease progression is largely meager. This poor effect of HAART can be attributed to irreversible CNS damage occurred during the early disease course before the start of intervention, sustained neuroinflammation, viral replication and load in CNS while on HAART (Becker et al., 2011; Dahl et al., 2014). In- addition, an observational study also demonstrated the neurotoxic effect of HAART specifically by the antibiotics used as first line of treatment (Bacchus et al., 2013). Patients CD4 count also serve as a prognostic factor for HAART response against mental disorders as a low or nadir CD4 count indicate advanced disease state and immune damage.

\section{References}

Ancuta P, Kamat A, Kunstman KJ, et al., Microbial translocation is associated with increased monocyte activation and dementia in AIDS patients. PLoS One 2008; 3: e2516.

Antinori A, Arendt G, Becker JT, et al., Updated research nosology of HIV associated neurocognitive disorder.
Neurology. 2007; 69(18): 1789-1799.

Bacchus C, Cheret A, Avettand-Fenoël V, et al.,: A single HIV-1 cluster and a skewed immune homeostasis drive the early spread of HIV among resting CD4+ cell subsets within one month post-infection. PLoS One. 2013; 8(5): e64219.

Bonomi AE, Patrick DL, Bushnell DM, Martin M. Validation of the United States' version of the World Health Organization Quality of Life (WHOQOL) instrument. J Clin Epidemiol. 2000 Jan; 53(1):1-12.

Burgoyne RW, Tan DH. Prolongation and quality of life for HIV-infected adults treated with highly active antiretroviral therapy (HAART): a balancing act. The Journal of antimicrobial chemotherapy. 2008; 61(3): 469 273 .

Campbell JH, Hearps AC, Martin GE, et al.,: The importance of monocytes and macrophages in HIV pathogenesis, treatment, and cure. AIDS. 2014; 28(15): 2175-2187.

Corless IB, Kirksey KM, Kemppainen J, Nicholas PK, McGibbon C, Davis SM, et al., Lipodystrophy associated symptoms and medication adherence in HIV/AIDS. AIDS patient care and STDs. 2005; 19(9): 577 \pm 86 .

Cysique LA, Hey-Cunningham WJ, Dermody $\mathrm{N}$, et al.,: Peripheral blood mononuclear cells HIV DNA levels impact intermittently on neurocognition. PLoS One. 2015; 10(4): e0120488.

Cysique LA, Moffat K, Moore DM, et al.,: HIV, vascular and aging injuries in the brain of clinically stable HIV-infected adults: A 1H MRS Study. PLoS One. 2013; 8(4): e61738.

Fairall LR, Bachmann MO, Louwagie GM, et al., Effectiveness of antiretroviral treatment in a South African program: A cohort study. Arch Intern Med. 2008 Jan 14; 168(1): 86-93. 
Fairall LR, Bachmann MO, Louwagie GM, et al., Effectiveness of antiretroviral treatment in a South African program: A cohort study. Arch Intern Med. 2008 Jan 14; 168(1): 86-93.

Freund A, Orjalo AV, Desprez PY, et al.,: Inflammatory networks during cellular senescence: causes and consequences. Trends Mol Med. 2010; 16(5): 238246.

He J, Chen Y, Farzan M, et al.,: CCR3 and CCR5 are co-receptors for HIV-1 infection of microglia. Nature. 1997; 385(6617): 645-649.

Heaton RK, Clifford DB, Franklin DR, et al., HIV-associated neurocognitive disorders persist in the era of potent antiretroviral therapy: CHARTER Study. Neurology 2010; 75: 2087-96.

Heaton RK, Marcotte TD, Mindt MR, et al., The impact of HIV associated neuropsychological impairment on everyday functioning. J Int Neuropsychol Soc 2004; 10: 317-31.

Hinkin CH, Castellon SA, Durvasula RS, et al., Medication adherence among HIV+ adults: effects of cognitive dysfunction and regimen complexity. Neurology 2002; 59: 1944-50.

Isabel Ruiz Pérez, Antonio Olry de Labry Lima, Luis Sordo del Castillo, Jesús Rodríguez Baño, Miguel Ángel López Ruz, Alfonso del Arco Jimenez. No differences in quality of life between men and women undergoing HIV antiretroviral treatment: Impact of demographic, clinical and psychosocial factors. AIDS Care. 2009; 21(8): 943952.

Janssen RS, Cornblath DR, Epstien LG. Nomenclature and research case definition for neurologic manifestation of human immunodeficiency virus-type(HIV1) infection. Report of a working group of the American Academy of Neurology AIDS Task Force.
Neurology. 1991; 41(6): 778-785.

Jelsma J, Maclean E, Hughes J, Tinise X, Darder M. An investigation into the health-related quality of life of individuals living with HIV who are receiving HAART. AIDS Care. 2005; 17(2): 579-588.

Lavi E, Strizki JM, Ulrich AM, et al.,: CXCR-4 (Fusin), a co-receptor for the type 1 human immunodeficiency virus (HIV-1), is expressed in the human brain in a variety of cell types, including microglia and neurons. Am J Pathol. 1997; 151(4): 1035-1042.

Louwagie GM, Bachmann MO, Meyer K, Booysen F le R, Fairall LR, Heunis C. Highly active antiretroviral treatment and health related quality of life in South African adults with human immunodeficiency virus infection: A cross-sectional analytical study. BMC Public Health. 2007; 7: 244.

Moore RD, Chaisson RE. Natural history of HIV infection in the era of combination antiretroviral therapy. AIDS. 1999 Oct 1; 13(14): 1933-42.

Moore RD, Chaisson RE. Natural history of HIV infection in the era of combination antiretroviral therapy. AIDS. 1999 Oct 1; 13(14): 1933-42.

Murri R, Fantoni M, Del Borgoc, et al., Determinants of Health-related quality of life in HIV-infected patients. AIDS Care. 2003 Aug; 15(4): 581-90.

NACO, Ministry of Health and Family Welfare, Government of India. India HIV Estimations 2015 Technical Report. New Delhi. 2016. p. 3.

National AIDS Control Organisation, Department of AIDS Control. Annual Report 2013-2014. New Delhi: Ministry of Health and Family Welfare, Government of India; 2014. p. 9-12.

Nicholas PK, Kirksey KM, Corless IB, Kemppainen J. Lipodystrophy and quality of life in HIV: symptom 
management issues. Applied nursing research: ANR. 2005; 18(1): 55 \pm 8 .

NIMH. HIV/AIDS and mental hEalth. Maryland: National Institute of Mental Health (NIMH), 2016.

Saylor D, Dickens AM, Sacktor N, et al., HIV-associated neurocognitive disorder-pathogenesis and prospects for treatment. Nat Rev Neurol 2016; 12: 234-48.

Signh D. What is in name? AIDS dementia complex, AIDS dementia complex, HIV associated dementia, HIV associated neurocognitive disorder or HIV encephalopathy. Afr J Psychiatry. 2012; 15(3): 172-175.

Sow PS, Otieno LF, Bissagnene E, et al., Implementation of an antiretroviral access program for HIV-1-infected individuals in resource-limited settings: Clinical results from 4 African countries. J Acquir Immune Defic Syndr. 2007; 44(3): 262-267.

Sow PS, Otieno LF, Bissagnene E, et al., Implementation of an antiretroviral access program for HIV-1-infected individuals in resource-limited settings: Clinical results from 4 African countries. J Acquir Immune Defic Syndr. 2007; 44(3): 262-267.

Tozzi V, Balestra P, Murri R, et al.,
Neurocognitive impairment influences quality of life in HIV-infected patients receiving HAART. Int J STD AIDS 2004; 15: 254-9.

Vivithanaporn P, Heo G, Gamble J, et al., Neurologic disease burden in treated HIV/AIDS predicts survival: a population-based study. Neurology 2010; 75: 1150-8.

Watkins CC, Treisman GJ. Cognitive impairment in patients with AIDS prevalence and severity. Hiv Aids 2015; 7: 35-47.

WHO. Global summary of the AIDS epidemic, 2013. 2014. Retrieved June 24, 2015, 2014, from http://www.who.int/hiv/data/epi_core_d ec2014.png?ua=1(2017) Global AIDS Update 2017. AIDS info website.

Wig N, Lekshmi R, Pal H, Ahuja V Mittal CM, Agarwal SK. The impact of HIV/AIDS on the quality of life: A cross-sectional study in north India. Indian J Med Sci. 2006 Jan; 60(1): 3-12.

Zhu T, Muthui D, Holte S, et al.,: Evidence for human immunodeficiency virus type 1 replication in vivo in $\mathrm{CD} 14+$ monocytes and its potential role as a source of virus in patients on highly active antiretroviral therapy. J Virol. 2002; 76(2): 707-716.

\section{How to cite this article:}

Vinay Malik, Tung Vir Singh Arya and Kaushiki Mukhergee. 2019. Role of Hormonal Effects in Men and Women HIV Patients. Int.J.Curr.Microbiol.App.Sci. 8(05): 1680-1685. doi: https://doi.org/10.20546/ijcmas.2019.805.194 